\title{
Effects of In Vitro Corticosteroids on B Cell Activation, Proliferation, and Differentiation
}

\author{
Thomas R. Cupps, Theresa L. Gerrard, Reuben J. M. Falkoff, Gail Whalen, and Anthony S. Fauci \\ Laboratory of Immunoregulation, National Institute of Allergy and Infectious Diseases, \\ National Institutes of Health, Bethesda, Maryland 20205
}

\begin{abstract}
The present study demonstrates the graded effect of in vitro corticosteroids (CSs) on the different phases of $B$ cell activation, proliferation, and differentiation. Early events such as activation and proliferation of high-dose anti- $\mu$ or Staphylococcus aureusstimulated $B$ cells are profoundly suppressed by the presence of in vitro CSs. The suppressed proliferative response may be mediated by a direct effect on $B$ cells and/or modulation of accessory cell function. Later events in the $B$ cell cycle such as the proliferative response to $B$ cell growth factor after either in vivo or in vitro activation are less sensitive to the suppressive effects of in vitro CSs. The final events in the B cell cycle; namely, the differentiation to the immunoglobulin-producing state, is not suppressed by in vitro CSs. Indeed, depending on the systems employed, there is either no effect or enhancement of immunoglobulin secretion by the presence of in vitro CSs. The graded effect of in vitro CSs on the discrete phases of the $B$ cell activation, proliferation, and differentiation cycle provide new insights into the complex nature of CS-induced modulation of human $B$ cell responses.
\end{abstract}

\section{Introduction}

Corticosteroids (CSs) ${ }^{1}$ have assumed an important role in the treatment of a wide range of diseases, including those with inflammatory or immune-mediated components $(1,2)$. Many of these diseases are mediated in part by humoral mechanisms such as autoantibody production and/or immune complex deposition. Despite the clinical importance of CS, the precise mechanisms of CS-induced immunoregulation of immunoglobulin (Ig) production have not been clearly defined. This has been due in part to the fact that B cell function is usually measured as Ig production, which is the final terminal expres-

Address requests for reprints to Dr. Fauci, National Institutes of Health, Building 10, Room 11B-13, Bethesda, MD 20205.

Dr. Cupps's and Ms. Whalen's present address is Georgetown University Hospital, Division of Rheumatology, Immunology, and Allergy, Washington, DC 20007; Dr. Gerrard's present address is Division of Virology, Food and Drug Administration, Bethesda, MD 20205; Dr. Falkoff's present address is Kaiser Permanente, San Diego, CA 92111.

Received for publication 18 January 1984 and in revised form 12 October 1984.

1. Abbreviations used in this paper: AET-SRBC, 2-aminoethylisothiouronium bromide-treated sheep erythrocytes; BCGF, B cell growth factor; CS, corticosteroid; FCS, fetal calf serum; MLR-SN, mixed lymphocyte reaction supernatant; PFC, plaque-forming cell; PWM, pokeweed mitogen; SAC, Staphylococcus aureus Cowan strain I; TCD, $\mathrm{T}$ cell-depleted; UF, unfractionated.

The Journal of Clinical Investigation, Inc.

Volume 75, February 1985, 754-761 sion of the B cell activation pathway. Because little was known until recently about the various phases of the B cell cycle, virtually no information has been available concerning the direct effects of CSs on human B cells at different states of activation. Furthermore, most measurable B cell functions are regulated by one or more types of accessory cells (3). Therefore, the observed effects of CSs on B cell function may well be due to the effects on the immunoregulatory accessory cells.

Investigation in this and other laboratories has resulted in delineation of the sequential events in the human $B$ cell activation cascade (4-8). By using this model system, it has been shown that resting $B$ cells can be activated by a number of initial signals. After activation, the B cells are then capable of responding directly and sequentially to a number of $T$ cellderived growth and differentiation factors such as B cell growth factor (BCGF) and B cell differentiation factor. In the present study, we have utilized this model system of the B cell cycle to demonstrate the selective effects of in vitro CSs on various phases of B cell activation, proliferation, and differentiation.

\section{Methods}

Subjects. 14 healthy men and women aged 20-34 yr were studied.

Drugs. Hydrocortisone sodium succinate (Upjohn Co., Kalamazoo, MI) was reconstituted in RPMI 1640 before being used in the in vitro studies.

Standard cell separations. Heparinized blood was immediately diluted 1:1 (vol/vol) with iced phosphate-buffered saline (PBS) pH 7.4, and unfractionated (UF) mononuclear cell suspensions were obtained by Ficoll-Hypaque (Ficoll, Pharmacia Fine Chemicals, Piscataway, NJ; Hypaque, Winthrop Laboratories, New York) density centrifugation (9). The UF mononuclear cells were initially depleted of T cells by rosetting with 2-aminoethylisothiouronium bromide-treated sheep erythrocytes (AET-SRBC) followed by separation by Ficoll-Hypaque density centrifugation (10). Further $\mathrm{T}$ cell depletion was performed either by repeating the AET-SRBC separation or by incubating the AET-SRBC rosette-negative cells with Leu-1 (anti-pan T lymphocyte) mouse monoclonal antibody (Becton, Dickinson \& Co., Sunnyvale, CA) at $2 \mu \mathrm{g} / 10^{7}$ cells at $4^{\circ} \mathrm{C}$ for $45 \mathrm{~min}$. After this, $1 \mathrm{ml}$ of $25 \%$ rabbit serum per $10^{7}$ cells was added, and the mixture was incubated in a $37^{\circ} \mathrm{C}$ waterbath for $1 \mathrm{~h}$. The cells were then washed in RPMI 1640 and evaluated for the presence of monocytes by nonspecific esterase staining (11). Cell preparations with $>40 \%$ esterase-positive cells were further depleted of monocytes by adherence to plastic tissue culture flasks in $0.2 \%$ heat inactivated fetal calf serum (FCS) in RPMI 1640 in $5 \% \mathrm{CO}_{2}$ in air at $37^{\circ} \mathrm{C}$ for $15-30 \mathrm{~min}$. The percent of esterasepositive cells ranged between $30-40 \%$ of the $T$ cell-depleted cells (TCD). The adequacy of the $T$ cell depletion was demonstrated by the failure to respond to the $T$ cell mitogens, concanavalin A (Sigma Chemical Co., St. Louis, MO), phytohemagglutinin (Burroughs Wellcome Laboratories, Research Triangle Park, NC), and pokeweed mitogen (PWM; Gibco Laboratories, Grand Island Biological Co., Grand Island, NY).

In some experiments, the TCD fractions were further monocyte depleted as described previously (11), with slight modification. Briefly, 
UF mononuclear cells were suspended in $0.2 \%$ FCS in RPMI and incubated at $37^{\circ} \mathrm{C}$ for $30 \mathrm{~min}$ to allow adherence to $4-\mathrm{mm}$ glass beads ( $4 \mathrm{~mm}$; Kimble Div., Owens-Illinois, Inc., Toledo, OH). AET-SRBC rosetting cells were then depleted as described above, and the remainder of cells were incubated over Sephadex G-10 columns with 10\% FCS in RPMI 1640 for $15 \mathrm{~min}$ at $37^{\circ} \mathrm{C}$. The number of surface Ig-positive cells ranged between 70 and $85 \%$. The nonadherent cells that eluted from the column were $<5 \%$ esterase-positive and were used as monocytedepleted B cells.

Elutriator cell separations. In the studies involving elutriation separation of large and small peripheral blood B cells, UF mononuclear cells were harvested by lymphapheresis on a continuous flow centrifuge1 (Fenwall, Division of Travenol, Silver Spring, MD) as previously described (12) with minor modifications. Venous access was obtained through the antecubital fossa. Cells were harvested for $1-1.5 \mathrm{~h}$ resulting in $2-5 \times 10^{9}$ mononuclear cells in a volume of $300 \mathrm{ml}$. UF mononuclear cells were then harvested in the standard fashion. From the morphologic standpoint and functional capabilities, UF mononuclear cells harvested by this procedure are similar to peripheral blood mononuclear cells (Wilder, R. L., unpublished observations). The cells were rigorously monocyte depleted as described above. Small and large peripheral blood B cells were separated by counterflow centrifugation-elutriation (Beckman model J-6B, Beckman Instruments, Inc., Palo Alto, CA) as detailed previously for tonsillar B cell separations (13). Cell volume was measured with a Coulter Channelyzer (Coulter Electronics, Inc., Hialeah, FL). The small B cells were $70-90 \%$ surface Ig-positive and less than 1:200 esterase-positive. The large B cell fraction was $65-85 \%$ surface Ig-positive with less than 2:100 esterase-positive cells. Monocytes were also harvested by counterflow centrifugation-elutriation as previously described (14). The cells were then AET-SRBC rosette-depleted as noted above and irradiated with 2,000 rad using a ${ }^{137} \mathrm{Cs}$ source (Isomedix, Parsippany, NJ). The monocyte-enriched fractions were $>90 \%$ nonspecific esterase-positive.

Mitogens. Staphylococcus aureus Cowan strain I (SAC) was obtained from American Type Culture Collection (Rockville, MD), treated as previously described (15), and used at a final concentration of 1:50,000 ( $\mathrm{vol} / \mathrm{vol})$ unless otherwise stated. In cultures measuring blastogenic responses, the PWM was used at a final concentration of 1:100, phytohemagglutinin at $10 \mu \mathrm{g} / \mathrm{ml}$, and concanavalin A at $5 \mu \mathrm{g} / \mathrm{ml}$. The $\mathrm{F}(\mathrm{ab})_{2}^{\prime}$ goat antihuman $\mu$ chain-specific antibody (N. L. Cappel Laboratories, Inc., West Chester, PA) was used at a final concentration of 20-150 $\mu \mathrm{g}$ protein $/ \mathrm{ml}$.

Generation of mixed lymphocyte reaction supernatant (MLR-SN). The MLR-SN was made by co-culture of $10^{6}$ AET-SRBC rosettepositive cells with $10^{6}$ allogeneic AET-SRBC rosette-negative cells in $10 \%$ FCS in RPMI 1640 with $2 \mathrm{mM}$ glutamine at a final volume of 2 $\mathrm{ml}$ in 15-mm diam plastic wells (Linbro Division, Flow Laboratories, Inc., New Haven, CT). The supernatants were harvested at $48 \mathrm{~h}$, aliquoted, and stored at $-20^{\circ} \mathrm{C}$ until use.

Generation of mitogen-stimulated crude $T$ cell-derived supernatants. Mitogen-stimulated crude $\mathrm{T}$ cell-derived supernatants were prepared from AET-SRBC rosette-positive cells $\left(2 \times 10^{6} / \mathrm{ml}\right)$ by culturing the cells in 10\% FCS in RPMI 1640 with $2 \mathrm{mM}$ gutamine in $15-\mathrm{mm}$ diam plastic wells at a final PWM concentration of 1:200 in a final volume of $2 \mathrm{ml}$ per well. The supernatants were harvested after $48 \mathrm{~h}$. Control supernatants (not stimulated by PWM) were obtained in a similar fashion except that PWM was added after the supernatant was harvested. Both PWM-induced and control supernatants were aliquoted and stored at $-20^{\circ} \mathrm{C}$ until used.

$B C G F$. Monoclonal BCGF from a human T-T cell hybridoma was used as previously described by Butler et al. (7).

Determination of sIg+ cells. B lymphocyte counts were determined in UF and B cell-enriched populations of cells by detection of sIg+ cells as previously detailed (16).

Blastogenesis. Cell proliferation was assayed by incorporation of tritiated thymidine on day 3 except as noted. Between $25 \times 10^{3}$ and $75 \times 10^{3}$ cells were cultured in $10 \%$ FCS, RPMI 1640 , with $10 \mu \mathrm{g} / \mathrm{ml}$ gentamicin in a final volume of $0.2 \mathrm{ml}$. Round-bottomed microtiter plates were used in experiments with TCD fractions, and flat-bottomed microtiter plates (Linbro Division, Flow Laboratories) were used in experiments involving extensively monocyte-depleted fractions (Linbro Division, Flow Laboratories). Approximately $16-20 \mathrm{~h}$ before harvesting on a Titertek cell harvester (Flow Laboratories), each well was pulsed with $1 \mu \mathrm{Ci}$ of tritiated thymidine $(6.7 \mathrm{Ci} / \mathrm{mM}$; New England Nuclear, Boston, MA). Incorporated radioactivity was counted on a liquid scintillation counter (model LS-350, Beckman Instruments, Inc., Fullerton, CA). Each point was done in triplicate.

Cell viability. Cell viability was determined at various times during the culture period by trypan-blue dye exclusion.

Determination of Ig-secreting cells. The ability of B lymphocytes to secrete Ig was measured in an indirect plaque-forming cell (PFC) assay using target SRBC coated with staphylococcal protein $A$ and a developing rabbit antihuman polyvalent (anti-IgG, + IgA, + IgM) antibody (Cappel Laboratories) as previously described in detail (16). Two protocols to stimulate TCD cell fractions to develop into Igsecreting cells were employed. In the first assay, $5 \times 10^{5}$ TCD cells were cultured in $10 \times 75-\mathrm{mm}$ plastic tubes in the presence of $10 \%$ FCS, RPMI 1640 with $2 \mathrm{mM}$ glutamine, gentamicin $1 \%$ with SAC 1: 50,000 (vol/vol) final concentration, and a final total volume of 1.0 $\mathrm{ml}$ as previously described (5). On the second day after the culture was set up, $0.5 \mathrm{ml}$ of the culture supernatant was removed and replaced with $0.5 \mathrm{ml}$ of MLR-SN. After $6 \mathrm{~d}$, a PFC assay was performed on the cultured cells in order to determine the number of Ig-secreting cells. In the second assay, $5 \times 10^{5} \mathrm{TCD}$ cells were cultured in $10 \%$ FCS, RPMI 1640 with $2 \mathrm{mM}$ glutamine, $1 \%$ gentamicin, and $0.5 \mathrm{ml}$ mitogen-stimulated crude $T$ cell-derived supernatant added at the beginning of the culture period to a total volume of $1 \mathrm{ml}$ in a $10 \times$ 75-mm plastic tube (17). These cultures were also harvested after $6 \mathrm{~d}$ in culture to determine the number of Ig-secreting cells.

B cell co-stimulatory assay. A human B cell co-stimulatory assay described by Muraguchi et al. (8) was used with minor modifications. The assay is designed to determine the synergistic effects of BCGF on the human B cell proliferative response after in vitro activation with SAC or anti- $\mu$. Briefly, $1 \times 10^{5}$ B cells were cultured in $0.2 \mathrm{ml}$ of $10 \%$ FCS, RPMI 1640 containing $2 \mathrm{mM}$ glutamine with (a) SAC 1:50,000 final dilution or $20 \mu \mathrm{g} / \mathrm{ml}$ protein anti- $\mu$ and (b) $50 \%$ by volume BCGF. Cultures were processed as previously noted. The degree of synergy in co-stimulatory cultures was determined by calculating the difference in counts between cultures with SAC or anti- $\mu$ alone and BCGF alone compared with cultures with both.

\section{Results}

Effect of in vitro hydrocortisone on $B$ cell proliferation. The effects of in vitro hydrocortisone sodium succinate on proliferative responses of B cells plus monocyte cell fractions (TCD cell populations) are shown in Fig. 1. There is a dosedependent suppression of both (Fig. $1 A$ ) SAC-stimulated and (Fig. $1 B$ ) high-dose anti- $\mu$-stimulated B cell proliferative responses in this population of cells. At $10^{-6} \mathrm{M}$ hydrocortisone, which is an in vivo obtainable pharmacologic dose (3), the SAC-stimulated response is $35 \%$ and the anti- $\mu$-stimulated response is $22 \%$ of the baseline proliferative response. A number of possibilities could be responsible for the CS-induced suppression of B cell proliferative responses: $(a)$ decreased viability of cultured cells; $(b)$ shift in the dose response or kinetic curves; $(c)$ modulation of the response by accessory cells such as monocytes; $(d)$ direct suppression of B cell function. Under culture conditions of the B cell proliferative assays, the mean ( \pm SEM) cell viability by trypan blue exclusion from five normals at the time of harvest (day 3) were as follows for cultures exposed to the following molar concentration of cortisone: control-97.5 $\pm 1.5,10^{-8}-91.8 \pm 2.7,10^{-7}$ $87.5 \pm 0.5,10^{-6}-88.0 \pm 2.7,10^{-5}-86.7 \pm 3.5,10^{-4}-89 \pm 4.1$. Clearly, 

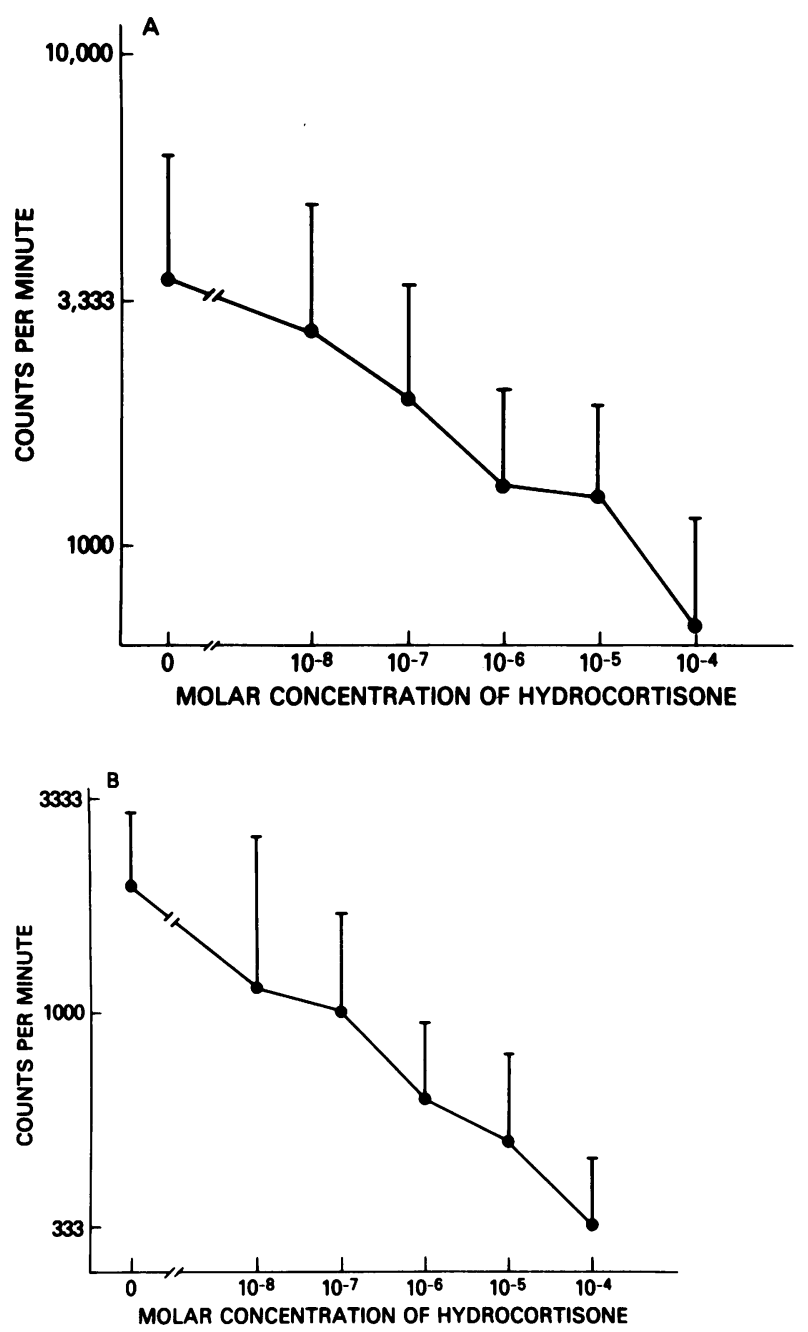

Figure 1. The effect of in vitro hydrocortisone on the geometric mean cpm of tritiated thymidine incorporation ( $\underset{\longrightarrow}{\longrightarrow} \mathrm{SEM})$ in B cellenriched populations from five normal individuals after stimulation with $(A)$ SAC or $(B)$ high-dose anti- $\mu$.

under the established culture conditions, the hydrocortisone did not alter viability of cultured B cells. The effect of varying concentrations of SAC and anti- $\mu$ on the CS-induced suppression of B cell proliferative responses is shown in Fig. 2. Although the absolute magnitude of the proliferative responses increases with increasing concentrations of SAC, the degree of CS-induced suppression is similar for the three concentrations evaluated. Similarly, dose-response curves up to 200 and 100 $\mu \mathrm{g} / \mathrm{ml}$ of anti- $\mu$ did not demonstrate a shift in the CS-induced suppression of the B cell proliferative response (Fig. 2 B). Kinetic studies in two separate experiments from day 2 to day 6 for both SAC-induced and anti- $\mu$-stimulated proliferation did not demonstrate a CS-induced shift of the peak response (data not shown). Thus, CS-induced suppression of SAC- and anti- $\mu$-stimulated B cell blastogenesis is not the result of altered cell viability, a change in the dose response curve, or a shift in the kinetic curve for peak proliferative responses.

Effect of in vitro hydrocortisone added at various times on $B$ cell proliferation. The time dependence of the in vitro CSinduced suppression of B cell proliferation is shown in Fig. 3. CS added after the initiation of culture and up to $1 \mathrm{~d}$ later significantly suppressed B cell proliferative responses. By the
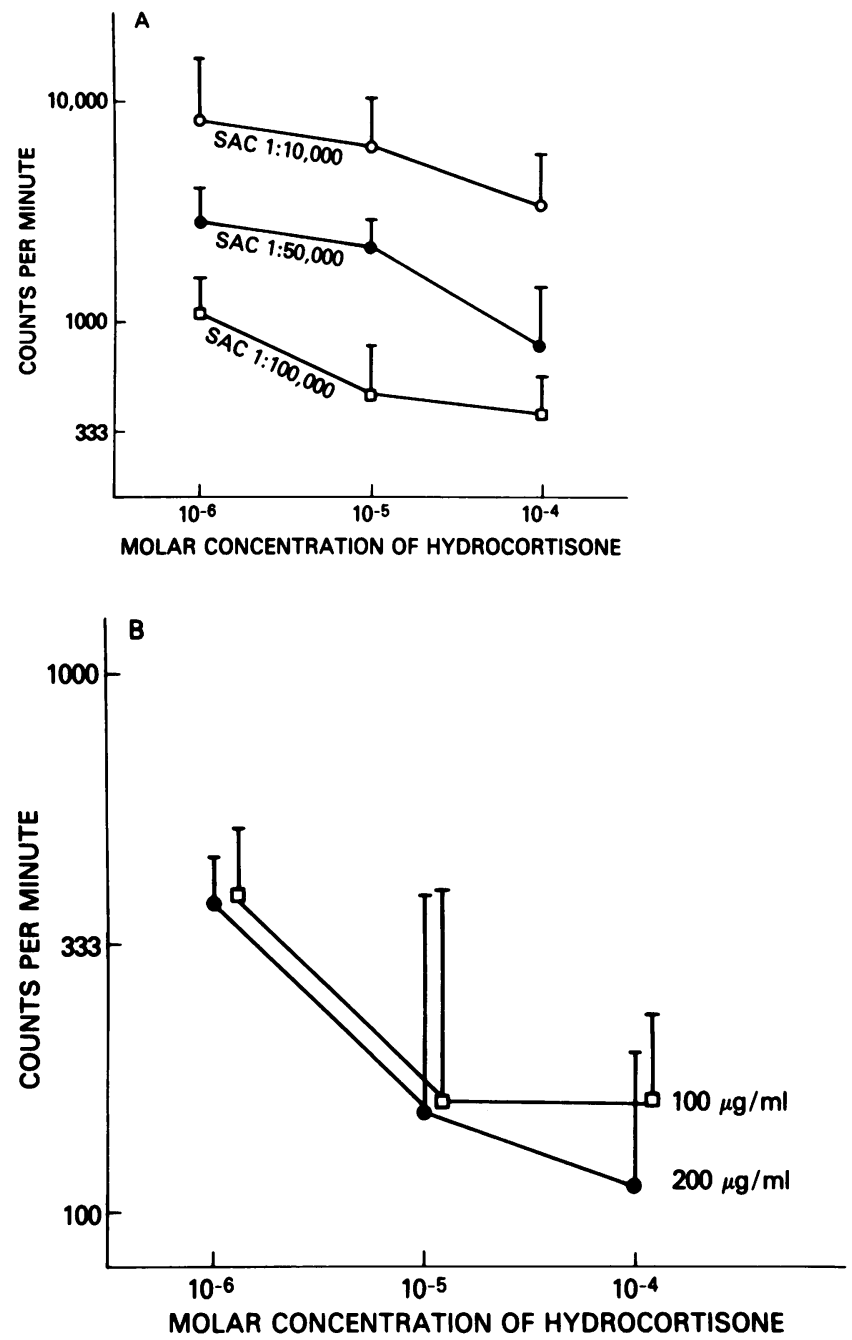

Figure 2. The effect of in vitro hydrocortisone on the geometric

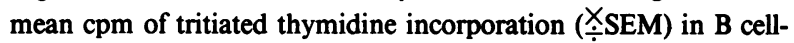
enriched populations from four individuals after stimulation with different concentrations of $(A)$ SAC or $(B)$ high-dose anti- $\mu$.

second day of culture, the addition of hydrocortisone had minimal effects on B cell proliferation.

Effect of monocytes on CS-induced suppression of B cell proliferation. To evaluate the role of accessory cell function in CS-induced modulation of B cell proliferative responses, studies were performed on cell fractions which had been rigorously depleted of monocytes (Fig. 4). In these monocyte-depleted fractions, CS-induced suppression of anti- $\mu$-stimulated B cell proliferation was unaltered (Fig. $4 \mathrm{~B}$ ). In contrast, rigorous monocyte depletion markedly altered the CS-induced suppression of SAC-induced B cell blastogenesis (Fig. 4 A). SACinduced B cell proliferation in the TCD fraction with $30-40 \%$ monocytes was suppressed to $37 \%$ of the baseline response by $10^{-6} \mathrm{M}$ hydrocortisone. In contrast, SAC-induced B cell proliferative response in rigorously monocyte-depleted $B$ cell fractions with $<1 \%$ monocytes was $85 \%$ of the baseline response in the presence of $10^{-6} \mathrm{M}$ hydrocortisone. Thus, the CSinduced suppression of B cell function is dependent on monocytes in certain systems (SAC stimulation) and independent of monocytes in other systems (anti- $\mu$ stimulation), suggesting that multiple mechanisms or action are operable in the suppression of B cell responses by CS. 


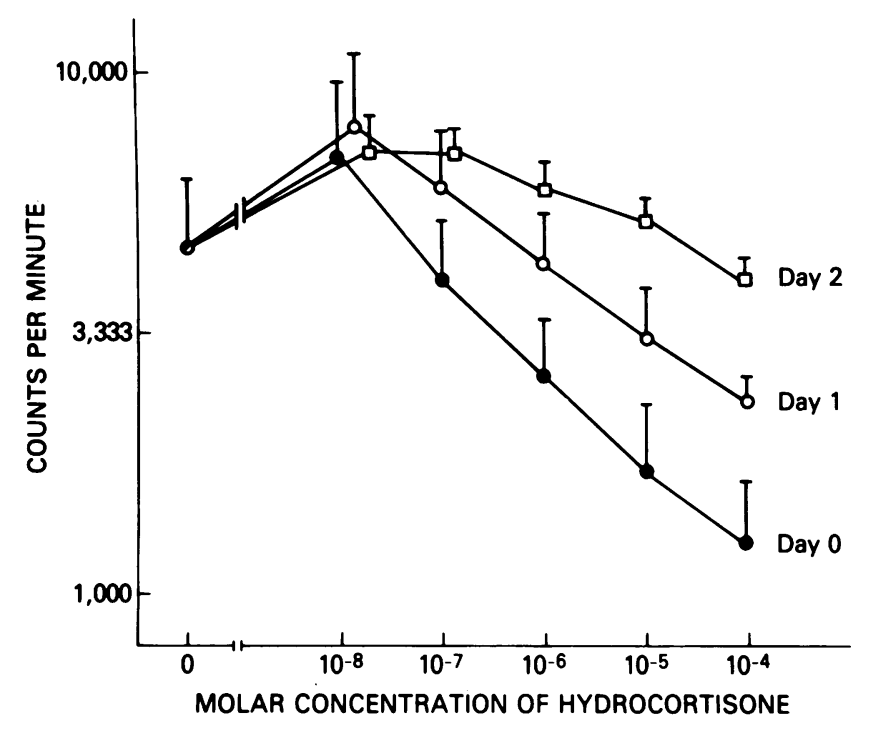

Figure 3. The effect of in vitro hydrocortisone added at various times on the geometric mean counts per minute of tritiated thymidine incorporation $(\stackrel{X}{\dot{\leftrightarrow}} \mathrm{SEM})$ in B cell-enriched populations from four normal individuals after stimulation with SAC. Hydrocortisone was added at the initiation of the culture (Day 0), the first day (Day 1), and the second day (Day 2).

Functional characterization of small and large peripheral blood B cells separated by counterflow centrifugation-elutriation. The functional characteristics of small and large peripheral blood B cells are summarized in Fig. 5. In the absence of in vitro stimulation, small B cells do not proliferate in response to monoclonal $\mathrm{BCGF}$ or mitogen-stimulated crude $\mathrm{T}$ cellderived supernatants (Fig. $5 A$ ). In contrast, large B cells, which presumably have been activated in vivo, respond directly to monoclonal BCGF and crude $\mathrm{T}$ cell-derived soluble factors. In addition, the majority of peripheral blood $B$ cells which will differentiate into PFC in the presence of $T$ cell supernatants are found in the large cell population (Fig. $5 \mathrm{~B}$ ). Control supernatants, prepared by using the protocol identical to the one used to prepare PWM-stimulated supernatants, except that the PWM was added at the end of the culture period, did not produce significant $B$ cell proliferation background counts (geometric mean [ $\stackrel{\times}{\longrightarrow} \mathrm{SEM}]$ of counts per minute for the unstimulated control $1,090 \stackrel{\times}{\lessgtr} 1.6$ and for the PWM supernatant control $989 \stackrel{\times}{\div} 1.3$, where $n=4$ ). The physical characteristics of activated cells found in the large B cell population in peripheral blood is similar to the physical characteristics described for tonsillar B cells using this method of cell separation (8). The presence of activated B cells in the large cell fractions separated from peripheral blood by percoll density gradients has been previously reported $(18,19)$.

Effect of in vitro hydrocortisone on the co-stimulation of $B$ cells by low-dose anti- $\mu$ and BCGF. After activation of normal B cells with low-dose anti- $\mu$, the addition of BCGF produces a synergistic or co-stimulatory effect on proliferation; namely, the degree of B cell proliferation in the presence of both anti$\mu$ and BCGF is greater than the sum of the proliferative responses in cultures containing either reagents alone (8). The effect of in vitro CS on the co-stimulatory response is shown in Fig. 6. There is less suppression of the co-stimulatory response compared with the CS-induced suppression of SAC

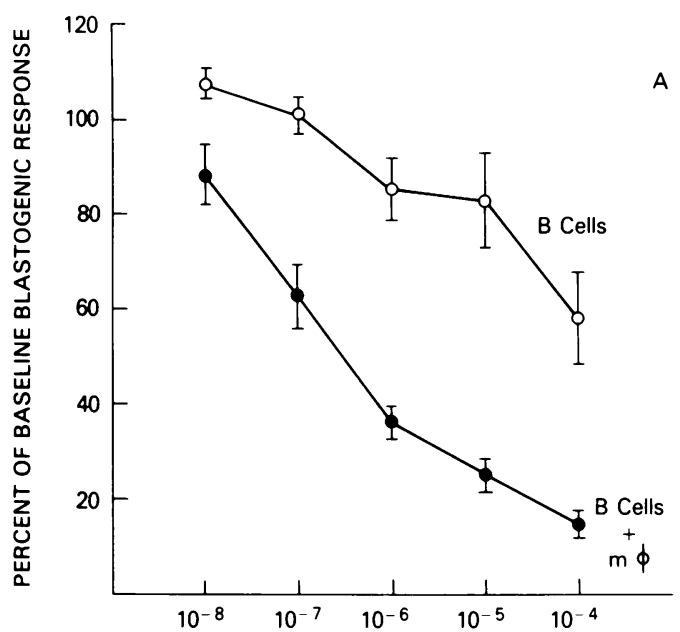

MOLAR CONCENTRATION OF HYDROCORTISONE

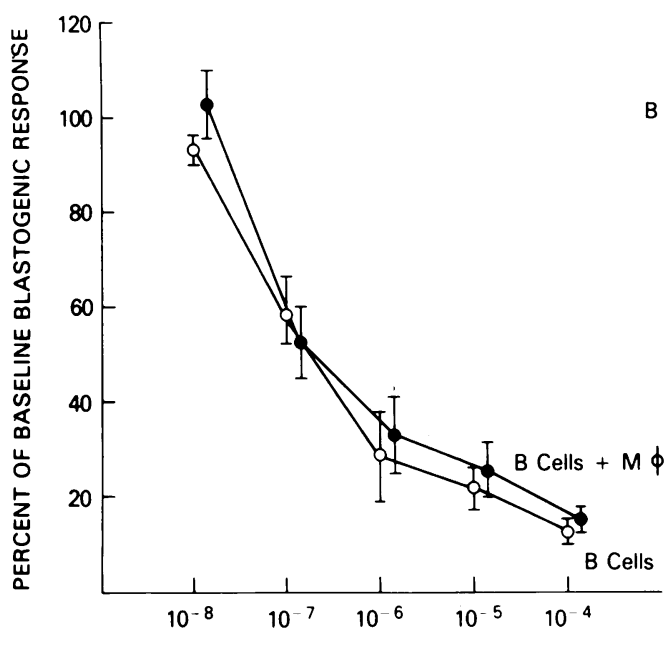

MOLAR CONCENTRATION OF HYDROCORTISONE

Figure 4. The effect of rigorous monocyte depletion on B cell blastogenesis expressed as the mean $( \pm \mathrm{SEM})$ of the percent of the baseline proliferative response following stimulation with $(A)$ SAC or $(B)$ highdose anti- $\mu$ in four normal individuals. B cells represent TCD fractions that have been monocyte-depleted to a level $<0.5 \%$ nonspecific esterase-positive cell. B cells $+\mathrm{M} \phi$ represent TCD fractions that contain between 20 and $38 \%$ nonspecific esterase-positive cells. The

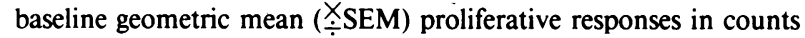
per minute were SAC-stimulated cells, $12,148 \stackrel{\times}{\div}$ 1.7; SAC-stimulated B cells $+\mathrm{M} \phi, 3,490 \stackrel{\times}{\leftarrow} 1.8$; high-dose anti- $\mu$-stimulated B cells, 5,929 $\stackrel{\times}{\div} 1.8$; and high-dose anti- $\mu$-stimulated B cells $+\mathrm{M} \phi, 1,784 \stackrel{\times}{\stackrel{\times}{\circ}} 1.8$.

and high-dose anti- $\mu$-stimulated B cell proliferation. For example, CS $\left(10^{-5} \mathrm{M}\right.$ hydrocortisone) suppresses the $\mathrm{B}$ cell proliferative response to SAC or high-dose anti- $\mu$ stimulation to $25 \%$ of the baseline response, while, in contrast, the same dose of in vitro CS only suppresses the B cell co-stimulatory response to $76 \%$ of the baseline response. Despite the presence of CS in culture, low-dose anti- $\mu$ can activate small peripheral blood B cells to the state where they can proliferate in the presence of BCGF.

Effect of in vitro hydrocortisone on the proliferative responses of large in vivo-activated B cells to BCGF or mitogen-stimulated crude $T$ cell-derived supernatants. As we have previously 

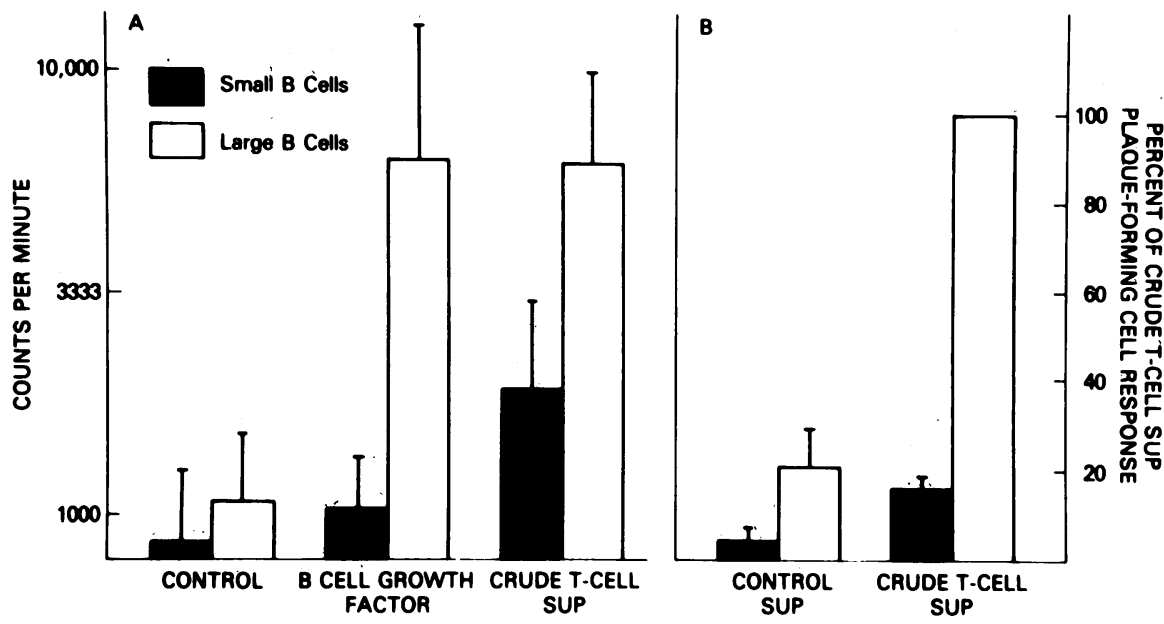

Figure 5. Functional parameters of small and large peripherál blood B cells separated by counterflow centrifugation elutriation from four individuals. $(A)$ The B cell proliferative responses expressed as the geometric mean of the counts per minute of tritiated thymidine incorporation ( $\underset{\perp}{\times} \mathrm{SEM})$ are shown. $(B)$ The PFC responise after culture with crude $T$-cell supernatant expressed as the percent of the peak response is shown. B cell growth factor, monoclonal B cell growth factor; crude $T$ cell sup, supernatant factors from PWM-stimulated T cells; control sup, supernatant factors prepared identically to the crudè $T$ cell sup except that the PWM was added at the end of the supernatant culture period. The geometric mean ( $\stackrel{X}{\times} \mathrm{SEM})$ of the peak PFC response was $5,098 \stackrel{\times}{\div} 2.6$ / $10^{6}$ cultured cells. demónstrated, large peripheral blood B cells which have presumably been activated in vivo proliferate (in the absence of an initial activating signal) to BCGF or $\mathrm{T}$ cell supernatant factors. The effect of in vitro CS on the large B cell proliferative response to BCGF or mitogen-stimulated crude $\mathrm{T}$ cell-derived supernatants is shown in Fig. 7. Again, there is less suppression of the large B cell proliferative response to BCGF and mitogenstimulated crude $\mathrm{T}$ cell-derived supernatants when compared to the CS-induced suppressions of SAC and high-dose anti- $\mu$ stimulated B cell proliferation. For example, CS $\left(10^{-5} \mathrm{M}\right.$ hydrocortisone) suppresses the B cell proliferative response to SAC or high-dose anti- $\mu$ to $25 \%$ of the baseline response, whereas, in contrast, the same dose of in vitro CS only suppressès the large B cell proliferative response to BCGF to $83 \%$ of the baseline response.

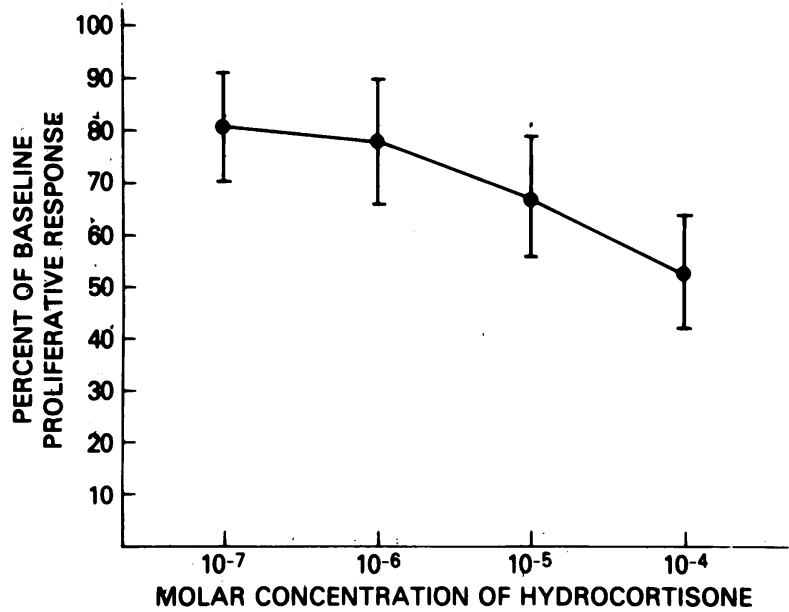

Figure 6. The effects of in vitro hydrocortisone on the co-stimulatory response of low-dose $(20 \mu \mathrm{g} / \mathrm{ml})$ anti- $\mu$ and B cell growth factor. The data are expressed as the mean percent $( \pm S E M)$ of the baseline costimulatory response in small peripheral blood B cells from four individuals. The geometric mean ( $\stackrel{\times}{\rightarrow} \mathrm{SEM})$ of tritiated thymidine incorporation in counts per minute in the four individuals was: un-

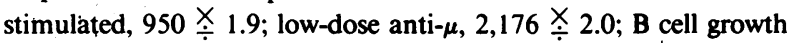
factor, $4,775 \stackrel{\times}{\div} 1.7$; anti- $\mu$ + B cell growth factor (co-stimulation), $18,389 \stackrel{\times}{-} 2.1$.
Effect of in vitro hydrocortisone on $B$ cell differentiation. The effect of in vitro hydrocortisone on the PFC responses after stimulation with SAC plus MLR-SN or after culture with mitogen-stimulated crude $\mathrm{T}$ cell-derived supernatants alone was measured (Fig. 8). When B cells are stimulated with SAC, there is a marked potentiation of PFC response in the presence of hydrocortisone. In contrast, in vitro CS do not appear to alter the PFC response of the B cell subpopulation which can differentiate in the presence of mitogen-stimulated crude $\mathrm{T}$ cell-derived supernatants alone without additional in vitro activation signals. A similar pattern was seen in studies using TCD cell fractions (data not shown). This observation suggests that the ability of in vitro CS to modulate Ig secretion may in part be dependent upon the stage of the cell in the B cell activation-differentiation cycle.

\section{Discussion}

The present study demonstrates the graded effect of in vitro CSs on $B$ cell activation, proliferation, and differentiation.

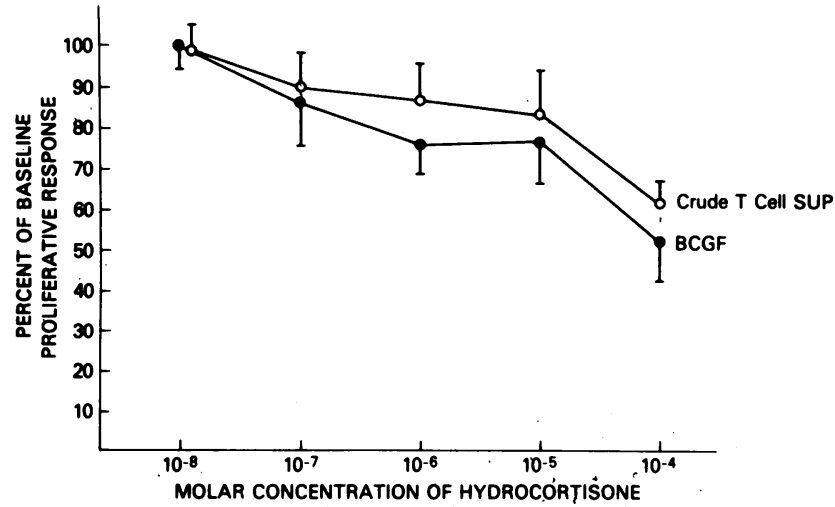

Figure 7. Effect of in vitro hydrocortisone on large, in vivo-activated peripheral B cell proliferative responses to B cell growth factor and crude $\mathrm{T}$-cell supernatant. The data are presented as the mean percent of the baseline proliferative count $( \pm$ SEM) from four normals. The baseline geometric mean ( $\underset{\div}{\mathrm{S}} \mathrm{SEM})$ proliferative response were for B cell growth factor stimulation $7,292 \stackrel{\times}{\div} 2.4$ and crude $T$ cell supernatant stimulation $3,783 \stackrel{\times}{\leftarrow} 1.5$. The large $\mathrm{B}$ cell preparations contain $<2 \%$ nonspecific esterase-positive cells. 


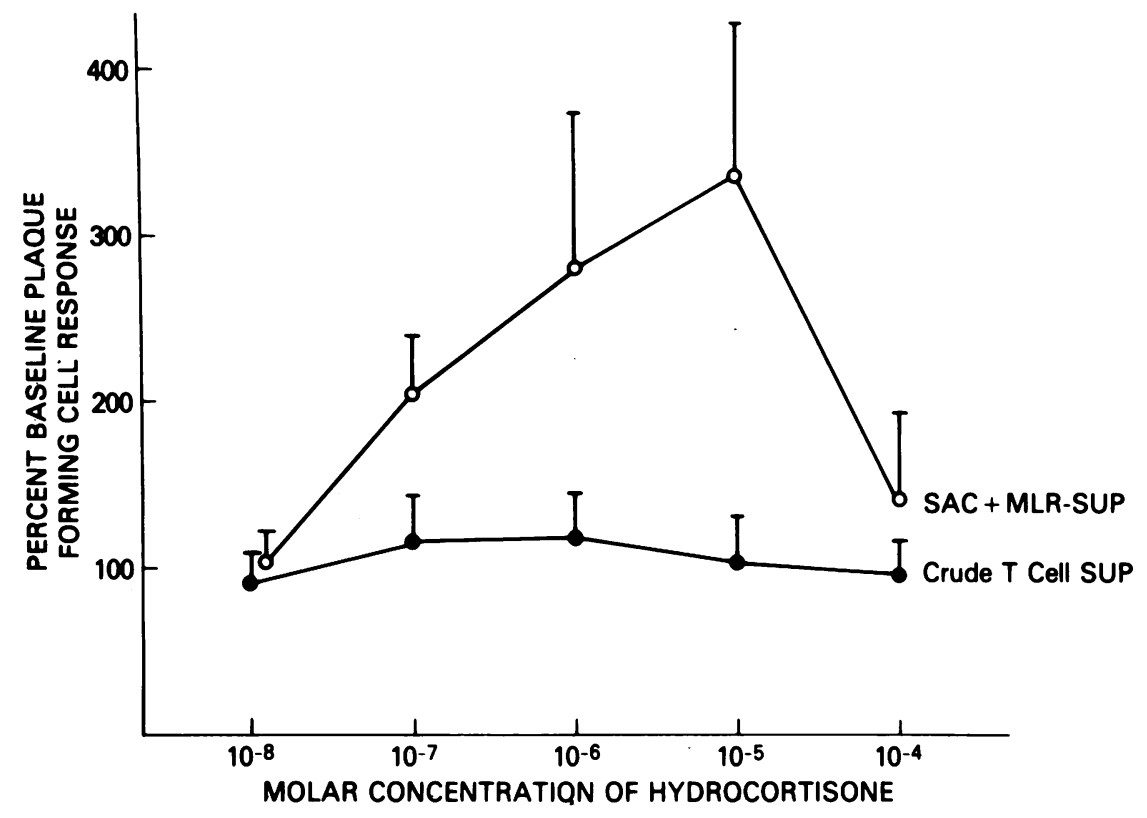

Figure 8. Effect of in vitro hydrocortisone on immunoglobulin production after stimulation with SAC plus MLR-SN or with crude T-cell supernatant alone. The data represent the mean percent of the baseline PFC response $( \pm$ SEM) in large peripheral blood B cells from four individuals. The geometric mean $(\stackrel{\times}{\div} \mathrm{SEM})$ of the peak PFC responses were for SAC plus MLR-SN 3,200 $\stackrel{\times}{\stackrel{\leftrightarrow}{-}} 1.95$ and crude $T$ cell supernatant $5,097 \stackrel{\times}{\div} 2.6 / 10^{6}$ cultured cells.
Early events in the B cell cycle such as the SAC and high-dose anti- $\mu$-induced $B$ cell activation and proliferation are profoundly suppressed by in vitro CS. To be effective, the CSs have to be present in culture during the first $24 \mathrm{~h}$, suggesting drug-induced modulation of an early event. Moreover, the presence of monocytes is important in the CS-induced supression of SACstimulated proliferative responses but not in high-dose anti- $\mu$ stimulated B cell proliferation, suggesting multiple mechanisms of actions. Intermediate steps such as activation of small peripheral blood B cells to a BCGF-responsive state (costimulation) are less sensitive to the suppressive effects of in vitro CS. Similarly, the response of large peripheral blood B cells which have presumably been activated in vivo to a BCGFresponsive state is also less sensitive to the suppressive effects of in vitro CSs. The later events of the B cell cycle, differentiation to an Ig secreting state, are relatively resistant to the suppressive effects of in vitro CSs. Indeed, depending on the experimental system employed, in vitro CSs have either no effect or actually potentiate Ig secretion. Thus, there is a graded sensitivity of the B cell activation, proliferation, and differentiation cycle to the suppressive effects of in vitro CSs, with early events being readily suppressed and later events being less sensitive or refractory to the suppressive effects of this drug.

Studies evaluating the effect of in vitro CSs on a B cell proliferative response are limited (20-22). Proliferative responses to PWM measured on day 5 and felt to represent B cell proliferation are reported to be relatively refractory to the suppressive effects of in vitro CSs (20). Similarly, PWMstimulated proliferation in B cell-enriched populations is relatively resistant to CS-induced suppression (21). Moreover, CSinduced suppression of PWM blastogenesis can be overcome by increasing the dose of the mitogen (22). In contrast,' we demonstrate that SAC and anti- $\mu$-stimulated B cell proliferation is suppressed substantially by in vitro CS. The disparity of findings probably reflect the difference in the mechanisms of $B$ cell activation. PWM requires the presence of accessory cells for B cell proliferation (21): Moreover, PWM appears to stimulate a partially activated subset of B cells (23). In contrast, human B cell proliferation in direct response to anti- $\mu$ and SAC can be readily demonstrated despite extensive accessory cell depletion $(8,24)$ and appear to act through the surface Ig receptor $(25,26)$.

There are several potential explanations for the observed in vitro CS-induced suppression of B cell proliferative responses including: $(a)$ decreased cell viability, $(b)$ shift in the kinetics of the proliferative response, $(d)$ altered dose response curves, (e) direct effect on responding B cell population, or $(f)$ indirect effects mediated through altered accessory cell function. The suppressed B cell proliferative responses in this study are not the result of altered cell viability or changes in kinetic curves or dose responses.

There is a dichotomy in the effect of rigorous monocyte depletion on CS-induced suppression of SAC-induced and anti- $\mu$-stimulated B cell proliferation. Rigorous monocyte depletion of anti- $\mu$-stimulated B cells has no effect on the CSinduced supression of proliferation. This observation suggests that CS may directly affect the B cell rather than modulate the response through an accessory cell such as monocytes for high-dose anti- $\mu$-stimulated proliferation. In contrast, CS-induced suppression of SAC-stimulated $B$ cell proliferation is dependent upon the presence of monocytes in the culture. Rigorous monocyte deletion greatly lessens CS-induced suppression of SAC-induced B cell proliferation. The importance of CS-induced effects on monocyte function in the modulation of lymphocyte-mediated aspects of the immune response has been emphasized (3). CS-induced modulation of lymphokine production is instrumental in suppressing $T$ cell functional capabilities $(27,28)$. Studies done in the mouse suggest that CS modulation of macrophage interleukin-1 production with subsequent suppression of interleukin-2 production is an important mechanism in CS-induced suppression of $T$ cell proliferative responses $(29,30)$. In addition, CS-induced modulation of release of monocyte-soluble factors other than interleukin-1 is recognized (31). Modulation of other monocytederived soluble factors remains a potential mechanism for the apparent monocyte dependence in the CS-induced suppression of SAC-stimulated B cell proliferation. Alternatively, in vitro 
CSs alter the maturation sequence of and accessory cell function of cultured human monocytes $(32,33)$.

In contrast to the profound suppression of the SACstimulated and high-dose anti- $\mu$-stimulated responses, B cell proliferation to BCGF is much less sensitive to the suppressive effects of in vitro CSs. The activation of small resting B cells by low doses of anti- $\mu$ to BCGF-responsive states is only suppressed by high concentrations $\left(10^{-4} \mathrm{M}\right.$ hydrocortisone) of in vitro CSs. In addition, large peripheral blood B cells, which have been activated in vivo to a BCGF-responsive state, are less sensitive to the suppressive effects of in vitro CSs. This latter step in the B cell activation, proliferation, and differentiation cycle; namely, B cell proliferation to BCGF, is much less sensitive to the suppressive effects of in vitro CSs when compared to the profound CS-induced suppression of SAC and high-dose anti- $\mu$-stimulated B cell proliferation.

In contrast to the CS-induced suppression of B cell activation and proliferation, B cell differentiation to an Ig-produced state is either unaltered or enhanced by the presence of in vitro CSs depending on the experimental system employed. The effect of in vitro CSs on Ig production is variable depending on a number of experimental parameters (3). For example, in certain systems, in vitro Ig production is enhanced by the presence of CS in culture (34-37). The CS-induced potentiation of the SAC-stimulated PFC responses is in agreement with these previously noted observations. However, the PFC response after stimulation of larger in vivo-activated B cells with soluble $T$ cell factors was unaltered by in vitro CS. CSs appear to be able to potentiate Ig production in systems that require the presence of an in vitro activation signal. In the system where the B cells have been activated in vivo and only seem to require the presence of a soluble $\mathrm{T}$ cell factor to differentiate, in vitro CSs did not appear to suppress or enhance the response. Taken together, these observations suggest that CSs modulate the B cell differentiation responses earlier in the B cell activation sequence. Cells further along the B cell differentiation cycle are relatively refractory to the immunomodulatory effect of in vitro CSs.

It is obvious from this report that immunomodulation of $B$ cell responses by in vitro CSs is quite complex. Different phases of the B cell cycle have a graded sensitivity to the immunomodulatory effects of in vitro CSs. The ability to evaluate the discrete events in the B cell activation-proliferation-differentiation cycle provides insights into the complex and multifaceted immunomodulatory effects of CS. Hopefully, these studies will provide insights towards our understanding not only the effects of CS on B cell function but also the impact of CS treatment on diseases characterized by abnormalities of B cell reactivity.

\section{Acknowledgments}

We gratefully acknowledge the kind gift of monoclonal BCGF by Dr. Joseph L. Butler and Dr. Julian L. Ambrus, Jr. The editorial skills of Ms. Ann C. London are especially appreciated.

\section{References}

1. Thorn, G. W. 1966. Clinical considerations in the use of corticosteroids. N. Engl. J. Med. 274:775-781.

2. Fauci, A. S., D. C. Dale, and J. E. Balow. 1976. Glucocortico- steroid therapy: mechanisms of action and clinical considerations. Ann. Intern. Med. 84:304-315.

3. Cupps, T. R., and A. S. Fauci. 1982. Corticosteroid-mediated immunoregulation in man. Immunol. Rev. 65:133-155.

4. Kishimoto, T., T. Miyake, Y. Nishizawa, T. Watanabe, and Y. Yamamura. 1975. Triggering mechanisms of B lymphocytes. I. Effect of anti-immunoglobulin and enhancing soluble factor on differentiation and proliferation of B cells. J. Immunol. 115:1179-1184.

5. Falkoff, R. J. M., L. P. Zhu, and A. S. Fauci. 1982. Separate signals for human $\mathrm{B}$ cell proliferation and differentiation in response to Staphylococcus aureus: evidence for a two-signal model of B cell activation. J. Immunol. 129:97-102.

6. Muraguchi, A., T. Kasahara, J. J. Oppenheim, and A. S. Fauci. 1982. B cell growth factor and $T$ cell growth factor produced by mitogen-stimulated normal human peripheral blood $\mathrm{T}$ cells are distinct molecules. J. Immunol. 129:2486-2489.

7. Butler, J. L., A. Muraguchi, H. C. Lane, and A. S. Fauci. 1983. Development of a human T-T cell hybridoma secreting B cell growth factor. J. Exp. Med. 157:60-68.

8. Muraguchi, A., J. L. Butler, J. H. Kehrl, and A. S. Fauci. 1983. Differential sensitivity of human B cell subsets to activation signals delivered by anti- $\mu$ antibody and proliferative signals delivered by a monoclonal B cell growth factor. J. Exp. Med. 157:530-546.

9. Cupps, T. R., L. C. Edgar, and A. S. Fauci. 1982. Suppression of human B lymphocyte function by cyclophosphamide. J. Immunol. 128:2453-2457.

10. Falkoff, R. M., M. Peters, and A. S. Fauci. 1982. T cell enrichment and depletion of human peripheral blood mononuclear cell preparations: unexpected findings in the study of the functional activities of the separated populations. J. Immunol. Methods. 50:3949.

11. Gerrard, T. L., and A. S. Fauci. 1982. Activation and immunoregulation of antigen-specific human B lymphocyte responses. Multifaceted role of the monocyte. J. Immunol. 128:2367-2372.

12. Karsh, J., J. H. Klippel, P. H. Plotz, J. L. Decker, and M. W. Flye. 1981. Lymphapheresis in rheumatoid arthritis. Arthritis Rheum. 24:857-873.

13. Muraguchi, A., J. L. Butler, J. H. Kehrl, R. J. M. Falkoff, and A. S. Fauci. 1983. Selective suppression of an early step in human B cell activation by cyclosporin A. J. Exp. Med. 158:690-702.

14. Gerrard, T. L., C. H. Jurgensen, and A. S. Fauci. 1984. Differential effect of monoclonal anti-DR antibody on monocytes in antigen and mitogen stimulated responses: mechanisms of inhibition and relationship to interleukin 1 secretion. Cell. Immunol. 82:394402.

15. Sjöberg, O., and J. Kurnick. 1980. Conditions for induction of specific and polyclonal antibody production by Cowan I bacteria and by pokeweed mitogen. Scand. J. Immunol. 11:47-51.

16. Fauci, A. S., G. Whalen, and C. Burch. 1980. Activation of human B lymphocytes. XVI. Cellular requirements, interactions, and immunoregulation in pokeweed mitogen-induced total-immunoglobulin-producing plaque-forming cells in peripheral blood. Cell. Immunol. 54:230-240.

17. Hirano, T., T. Kuritani, T. Tadamitsu, and Y. Yamamura. 1977. In vitro immune response of human peripheral lymphocytes. I. The mechanism(s) involved in $\mathrm{T}$ cell helper functions in the pokeweed mitogen-induced differentiation and proliferation of B cells. J. Immunol. 119:1235-1241.

18. Kuritani, T., and M. D. Cooper. 1982. Human B cell differentiation. II. Pokeweed mitogen responsive B cells belong to a surface immunoglobulin D-negative population. J. Exp. Med. 155:1561-1566.

19. Kuritani, T., and M. D. Cooper. 1983. Human B cell differentiation. IV. Effect of monoclonal anti-immunoglobulin $M$ and $D$ antibodies on B cell proliferation and differentiation induced by $T$ cell factors. J. Immunol. 131:1306-1311.

20. Heilman, D. H., M. R. Gambrill, and J. P. Leichner. 1973. The effect of hydrocortisone on the incorporation of tritiated thymidine 
by human blood lymphocytes cultured with phytohemagglutinin and pokeweed mitogen. Clin. Exp. Immunol. 15:203-212.

21. Blomgren, H., and B. Andersson. 1976. Steroid sensitivity of PHA and PWM responses of fractionated human lymphocytes in vitro. Exp. Cell Res. 97:233-240.

22. Gordon, D., and A. M. E. Nouri. 1981. Comparison of the inhibition of glucocorticosteroids and cyclosporin A of mitogen-stimulated human lymphocyte proliferation. Clin. Exp. Immunol. 44:287294.

23. Kuritani, T., and M. D. Cooper. 1982. Human B cell differentiation. II. Pokeweed mitogen-responsive B cells belong to a surface immunoglobulin D-negative subpopulation. J. Exp. Med. 155:15611566.

24. Falkoff, R. J. M., A. Muraguchi, J.-X. Hong, J. L. Butler, C. A. Dinarello, and A. S. Fauci. 1983. The effects of interleukin 1 on human B cell activation and proliferation. J. Immunol. 131:801-805.

25. Fothergill, J. J., R. Wistar, Jr., J. N. Woody, and D. C. Parker. 1982. A mitogen for human B cells: anti-Ig coupled to polyacrylamide beads activated blood mononuclear cells independently of $T$ cells. $J$. Immunol. 128:1945-1949.

26. Romagnani, S., M. G. Giudizi, R. Biagiotti, F. Almerigognia, E. Maggi, G. Del Prete, and M. Ricci. 1981. Surface immunoglobulins are involved in the interaction of protein A with human B cells and in the triggering of $B$ cell proliferation induced by protein A-containing Staphylococcus aureus. J. Immunol. 127:1307-1313.

27. Gillis, S., G. R. Crabtree, and K. A. Smith. 1979. Glucocorticoidinduced inhibition of $\mathrm{T}$ cell growth factor production. $\mathrm{I}$. The effect on mitogen-induced lymphocyte proliferation. J. Immunol. 123:16241631 .

28. Gillis, S., G. R. Crabtree, and K. A. Smith. 1979. Glucocorticoidinduced inhibition of $\mathrm{T}$ cell growth factor production. II. The effect on the in vitro generation of cytolytic T cells. J. Immunol. 123:16321638 .
29. Smith, K. S. 1980. T-cell growth factor. Immunol. Rev. 51:337357.

30. Synder, D. S., and E. R. Unanue. 1982. Corticosteroids inhibit murine macrophage Ia expression and interleukin 1 production. $J$. Immunol. 129:1803-1805.

31. Werb, Z. 1978. Biochemical actions of glucocorticosteroids on macrophages in culture. Specific inhibition of elastase, collagenase, and plasminogen activator secretion and other metabolic function. $J$. Exp. Med. 147:1695-1712.

32. Rinehart, J. J., D. West, and G. A. Ackerman. 1982. Corticosteroid alteration of human monocyte to macrophage differentiation. J. Immunol. 129:1436-1440.

33. Maynerik, D. G., A. Ul-Haq, and J. J. Rinehart. 1983. Differentiation-associated alteration in human monocyte-macrophage accessory cell function. J. Immunol. 130:2156-2160.

34. Smith, R. W., W. A. Sherman, and E. Middleton, Jr. 1972. Effect of hydrocortisone on immunoglobulin synthesis and secretion by human peripheral lymphocytes in vitro. Int. Arch. Allergy Appl. Immunol. 43:859-870.

35. Fauci, A. S., K. R. Pratt, and G. Whalen. 1977. Activation of human B lymphocytes. IV. Regulating effects of corticosteroids on the triggering signal in the plaque-forming response of human peripheral blood B lymphocytes to polyclonal activation. J. Immunol. 119:598603.

36. Cooper, D. A., M. Duckett, V. Petts, and R. Penny. 1979. Corticosteroid enhancement of immunoglobulin synthesis by pokeweed mitogen-stimulated human lymphocytes. Clin. Exp. Immunol. 37:145151.

37. Grayson, J., N. J. Dooley, I. R. Koski, and R. M. Blease. 1981. Immunoglobulin production induced in vitro by glucocorticoid hormones. $T$ cell-dependent stimulation of immunoglobulin production without B cell proliferation in cultures of human peripheral blood. $J$. Clin. Invest. 68:1539-1547. 